\begin{tabular}{|c|c|c|}
\hline & Int.J.Curr.Microbiol.App.Sci (2021) 10(09): 128-139 & \\
\hline & $\begin{array}{l}\text { International Journal of Current Microbiology and Applied Sciences } \\
\text { ISSN: 2319-7706 Volume } \mathbf{1 0} \text { Number } 09 \text { (2021) } \\
\text { Journal homepage: http://www.ijcmas.com }\end{array}$ & $\$ 20$ \\
\hline $\begin{array}{l}\text { EXCELLENT } \\
\text { PUBLISHERS }\end{array}$ & & \\
\hline
\end{tabular}

\title{
A Retrospective Study of COVID-19 Cases Based on Age and Gender in Patient's Visiting Tertiary Care Centre, Tezpur Medical College and Hospital, Tezpur, Assam
}

\author{
Syed Tanwir Alam ${ }^{1}$, Samrat Biswas ${ }^{1}$, Kalpana Bezborah ${ }^{2}$, Sonuwara Begum $^{1}$, \\ Mihirjyoti Pathak ${ }^{1}$, Saurav Phukan ${ }^{1}$, Pitambar Baishya ${ }^{1}$, Kaushik Das ${ }^{1}$, \\ Jasbeer Singh Roy ${ }^{2}$, Sanjay Sarkar ${ }^{2}$, Simi Borah ${ }^{2}$ and Miranda Khuttiya ${ }^{2}$ \\ ${ }^{1}$ Viral Research and Diagnostics Laboratory, ${ }^{2}$ Department of Microbiology, Tezpur Medical \\ College \& Hospital, Bihaguri-784010, Tezpur, Assam, India \\ *Corresponding author
}

Keywords

SARS-CoV-2, COVID-19,

Psychological, Viral Transport Media,

Containment

Article Info

Accepted:

10 August 2021

Available Online:

10 September 2021
Severe acute respiratory syndrome coronavirus 2 (SARS-CoV-2) which is also called COVID-19 has affected millions of people globally and has led to unprecedented disruptions to health systems, as well as affected individuals social, economic and psychological lives very badly. The present study was an attempt to address the association between age and gender among positive COVID-19 cases and also to discuss the possible reasons for the variation among age categories and gender. This was a retrospective based study. Samples were collected in Viral Transport Media and sent to the testing laboratory for confirmation by nucleic acid-based reverse transcription polymerase chain reaction (RT-PCR). Data regarding patients' details were collected in the hospital facility. A total of 1,11,379 (Assam - 1,08,836 and Arunachal Pradesh-2543) samples were collected from patient's and tested for COVID-19 (April to December 2020). During this period a total of 2,600 positive cases were detected at the laboratory from Assam $(n=2,480,95.38 \%)$ and Arunachal Pradesh $(n=120,4.62 \%)$ respectively. Males $(n=2106,81 \%)$ was affected more than females $(n=$ $494,19 \%)$. In both male \& female the age group which was affected the most was between 20-29 yrs and 30-39 yrs. Month wise distribution of the positive COVID-19 cases showed maximum spike in the month of August $(n=902)$. Early diagnosis by real time PCR has helped in the identification of the pathogen in individuals at an early stage, which has facilitated the containment of positive cases. 


\section{Introduction}

A novel coronavirus (SARS-CoV-2) that originated from Wuhan in the Hubei province of Central China has been linked to the outbreak of severe acute respiratory syndrome (Ghinai et al., 2020). The first case of COVID-19 was reported in humans on December 31, 2019. World Health Organization (WHO) declared the coronavirus disease (COVID-19) as a global pandemic on March 11, 2020 (Novel coronavirus disease 2019, 2020).

The overall current global situation of COVID-19 at present is around 132,730,691 confirmed cases with a death cases of about 2,880,726 (WHO Coronovirus (COVID-19) dashboard, 2021). The overall confirmed and death cases reported from different countries are as follows China confirmed cases 103,003 with a death case of 4,851 . The United Kingdom confirmed cases 4,367,295 with a death case of 126,927. United States of America confirmed cases $30,541,000$ with a death case of 552,928. Italy confirmed cases $3,700,393$ with a death case of 112,374 . Russain federation confirmed case 4,614,834 with a death case of 101,845 . Brazil confirmed case 276,890 with a death case of 12,366 (WHO Coronovirus (COVID-19) dashboard, 2021).

In India, the first case of COVID-19 was identified on January 30, 2020 from Kerala and the number has been increasing steadily due to local transmission and foci of community transmission. In India, a country of approximately 1.3 billion people, has reported 12,928,574 confirmed COVID-19 cases with a Death cases of 1,66,862 (WHO Coronovirus (COVID-19) dashboard, 2021). COVID-19 cases reported from other parts of states are as follows Assam confirmed cases 2,19,272 with a death cases of 1,112. Maharashtra confirmed cases $32,29,547$ with a death cases of 57,028. Kerala confirmed case of $11,48,948$ with a death case of 4,729 . Punjab confirmed case of 2,63,090 with a death case of 7,334. Tamil Nadu confirmed case of 9,15,386 with a death case of 12,840 (COVID-19 India, 2021).

Cases reported from neighboring countries of India are such as Nepal confirmed cases 278,768 with a death case of 3,038. Sri Lanka confirmed cases 93,993 with a death case of 591. Pakistan confirmed cases of 700,188 with a death cases of 15,026 and Bangladesh confirmed cases 659,278 with a death cases of 9,447 (WHO Coronovirus (COVID-19) dashboard, 2021).

\section{Virus}

The Virus (SARS -CoV-2) Coronavirus are positive sense single stranded RNA viruses having an extensive wide range of natural hosts and affect multiple systems (Weiss \& Leibowitz, 2011; Li et al., 2020). The SARSCoV-2 is a member of the order Nidovirales, family Coronaviridae, Genus Coronavirus sub-family Orthocoronavirinae, which is subdivided into four genera, viz. Alphacoronavirus, Betacoronavirus, Gammacoronavirus and Deltacoronavirus (Zhu et al., 2020; Chen et al., 2020). The size of virus ranges from 26 to 32 kilobases, they have characteristics club shaped spikes that project from their surface.

The role of age in transmission is critical to designing interventions aiming to decrease transmission in the population as a whole and to projecting the expected global burden. Our findings, together with early evidence16, suggest that there is age dependence in susceptibility and in the risk of clinical symptoms following infection with SARSCoV-2. SARS-CoV-2 has shown relatively low pathogenicity and moderate transmissibility. COVID-19 has affected 
people of all ages but older persons have been far more likely to suffer the most with severe health consequences. In humans the Coronavirus infection is commonly associated with mild to severe respiratory diseases that are characterized by high fever, severe inflammation, cough and internal organ dysfunction that can even lead to death (Kritas et al., 2020). Early diagnosis by real-time PCR and next-generation sequencing has facilitated the identification of the pathogen at an early stage.

India, a developing nation with a population of approximately 1.3 billion people initially took some of the strictest measures to slow down the spread of the coronavirus by putting nationwide lockdown, usage of masks in public places, hand sanitization, segregating affected person. The lockdown was effective and it was widely obeyed, but it could not be kept for longer time as the economy was affected badly so the Government have to prioritize reopening and accept the risks of surging coronavirus infections. Though high efforts have been put on to counter this virus but till date it has not been controlled.

The present study was an attempt to address the association between age and gender among positive COVID-19 cases and also to discuss the possible reasons for the variation among age categories and gender.

\section{Materials and Methods}

\section{Study Conduct}

The time period for the study was taken from April 2020 to December 2020. Consents of the patients were taken for collection of samples.

Samples were collected from patients suspected for COVID-19 and who have travelled from affected countries as well as from other parts of the states. Details of the patients which include age, sex, travel history, symptoms etc were recorded in standard specimen referral forms as per ICMR guidelines.

\section{Laboratory Confirmation}

Nasopharyngeal \& oropharyngeal swabs were collected in Viral Transport media (VTM) and sent to Viral Research \& Diagnostics Laboratory for RT-PCR test for the presence of SARS-CoV-2. Samples were tested for SARS-CoV-2 as per protocol (manufacturer guidelines) by using Viral RNA extraction kit and RT-PCR kits which was supplied by ICMR, New Delhi, India. Positive confirmed cases were shifted to isolation ward.

\section{Data analysis}

The data were analyzed by using XLSTAT (version 23.1.1094.0). Descriptive statistics, Chi-square tests were done and significance of tests was decided at $\mathrm{P}=0.05$.

\section{Results and Discussion}

\section{General Information}

A total of 1,11,379 samples suspected for Covid-19 were tested at Virus Research and Diagnostic Laboratory (VRDL), Tezpur Medical College and Hospital (TMCH), Assam during the period of April 2020 to December 2020.

Data regarding patients' details were collected in hospital facility. Of the total samples tested, the state of Assam contributed a total of $1,08,836$ samples and the state of Arunachal Pradesh contributed a total of 2,543 samples (Figure 1).During this period a total of 2,600 positive Covid-19 cases were detected at the laboratory from Assam $(n=2,480,95.38 \%)$ and Arunachal Pradesh $(\mathrm{n}=120,4.62 \%)$ respectively (Table1, Figure 2). 
Sonitpur district carried the maximum load of confirmed positive Covid-19 cases

Samples from 11 districts of Assam and some samples from Arunachal Pradesh were tested at the VRDL, TMCH laboratory. The samples included people having travel history and with no travel history. Out of the 2,600 total Covid19 cases detected, Sonitpur district was found to be the most affected district with $67.27 \%$ of the total cases which was followed by Udalguri district with $15.27 \%$ of the total cases. The other district showed variable distribution of the positive cases (Table 1, Figure 3).

\section{The month of August showed the maximum} spike in cases

There were no positive cases in the month of April, a gradual increase of positive cases was noted in the subsequent months. First case of COVID-19 was detected in VRDL, TMCH in the month of May 2020 which was followed by gradual increase in the positive cases. The Maximum Spike in cases was seen in the month of August 2020 which was followed by a gradual decline in the cases in the month of November $(\mathrm{n}=58)$ and December $(\mathrm{n}=5)$ (Figure 4).

Younger aged people were most susceptible to Covid-19 disease

Our observation revealed a rather different but interesting finding. Of all the positive COVID-19 cases that were detected at the laboratory, younger aged people were found to be more vulnerable to the disease. It may be noted that people aged between 20-29 yrs and 30-39 yrs showed the maximum spike in the positive cases in both males and females and significantly associated with the disease ( $\mathrm{p}$ value >0.000). Interestingly, out of the 2600 confirmed positive patients, only 30 cases were detected in the age group above $\geq 70$ yrs and understandably there was no significance association found in this age group ( $\mathrm{p}$ value $=$ 0.576). (Table 2, Figure 5).

\section{Females were less susceptible to COVID-19 as compared to males}

Of the $2600(2.33 \%)$ confirmed positive cases that were detected during the study period, a total of $2106(81 \%)$ patients were male and only $494(19 \%)$ patients were females. The above observations showed that males contracted the disease almost 4 times more than that of females (Table 2, Figure 6).

Our study demonstrated interesting trajectories of the COVID-19 cases in patient's based on gender and age groups as well as in different months. Our observation revealed that of all the positive COVID-19 cases that were detected at the laboratory, younger aged people were found to be more vulnerable to the disease. It may be noted that people aged between 20-29 yrs and 30-39 yrs showed the maximum spike in the positive cases in both males and females and significantly associated with the disease ( $\mathrm{p}$ value >0.000). Interestingly, out of the 2600 confirmed positive patients, only 30 cases were detected in the age group above $\geq 70$ yrs and understandably there was no significance association found in this age group ( $\mathrm{p}$ value $=$ 0.576 ). In our study the gender which was affected more was Males $(\mathrm{n}=2106,81 \%)$ than females $(n=494,19 \%)$. First case of COVID19 was detected in the month of May 2020 which was followed by gradual increase in the positive cases. The Maximum Spike in cases was seen in the month of August $(n=902)$ which was followed by a gradual decline in the cases in the month of November $(n=58)$ and December. 
Table.1 Distribution of COVID-19 cases in Assam (district wise) and Arunachal Pradesh.

\begin{tabular}{|c|c|c|}
\hline $\begin{array}{c}\text { Total case }=(n=2600 ; \operatorname{Assam}(2480) \text { and } \\
(120)\end{array}$ & & \\
\hline State & Total case & Percentage( $\%)$ \\
\hline Arunachal Pradesh & 120 & 4.62 \\
\hline \multicolumn{3}{|l|}{ Assam (Districts) } \\
\hline Sonitpur & 1749 & 67.27 \\
\hline Udalguri & 397 & 15.27 \\
\hline Darrang & 119 & 4.58 \\
\hline Biswanath Chariali & 96 & 3.69 \\
\hline Kamrup & 53 & 2.04 \\
\hline Nagaon & 21 & 0.81 \\
\hline Nalbari & 20 & 0.77 \\
\hline Korajhar & 17 & 0.65 \\
\hline Baksa & 5 & 0.19 \\
\hline Bongaigaon & 2 & 0.08 \\
\hline Chirang & 1 & 0.04 \\
\hline Total (Assam cases) & 2480 & 95.38 \\
\hline
\end{tabular}

Table.2 Age and Gender wise Distribution of Covid-19 Cases.

\begin{tabular}{|c|c|c|}
\hline \multirow{2}{*}{ Age (YEARS) } & \multicolumn{2}{|c|}{ Total Positive $=\mathbf{2 6 0 0}$} \\
\cline { 2 - 3 } & Male $(\boldsymbol{\%})$ & Female $(\%)$ \\
\hline $\mathbf{0}$ to $\mathbf{9}$ & $30(1.42)$ & $24(4.86)$ \\
\hline $\mathbf{1 0}$ to $\mathbf{1 9}$ & $113(5.37)$ & $46(9.31)$ \\
\hline $\mathbf{2 0}$ to $\mathbf{2 9}$ & $801(38.03)$ & $143(28.95)$ \\
\hline $\mathbf{3 0}$ to $\mathbf{3 9}$ & $622(29.53)$ & $116(23.48)$ \\
\hline $\mathbf{4 0}$ to $\mathbf{4 9}$ & $302(14.34)$ & $73(14.78)$ \\
\hline $\mathbf{5 0}$ to $\mathbf{5 9}$ & $160(7.60)$ & $60(12.15)$ \\
\hline $\mathbf{6 0}$ to $\mathbf{6 9}$ & $57(2.71)$ & $23(4.66)$ \\
\hline $\mathbf{7 0}$ to $\mathbf{7 9}$ & $16(0.76)$ & $5(1.01)$ \\
\hline $\mathbf{2} \mathbf{8 0}$ & $5(0.24)$ & $4(0.81)$ \\
\hline TOTAL & $\mathbf{2 1 0 6}(\mathbf{8 1})$ & $\mathbf{4 9 4}(\mathbf{1 9})$ \\
\hline
\end{tabular}


Fig.1 Distribution of samples between Assam and Arunachal Pradesh tested at Virus Research and Diagnostics Laboratory, Tezpur Medical College and Hospital starting from April 2020 to December 2020.

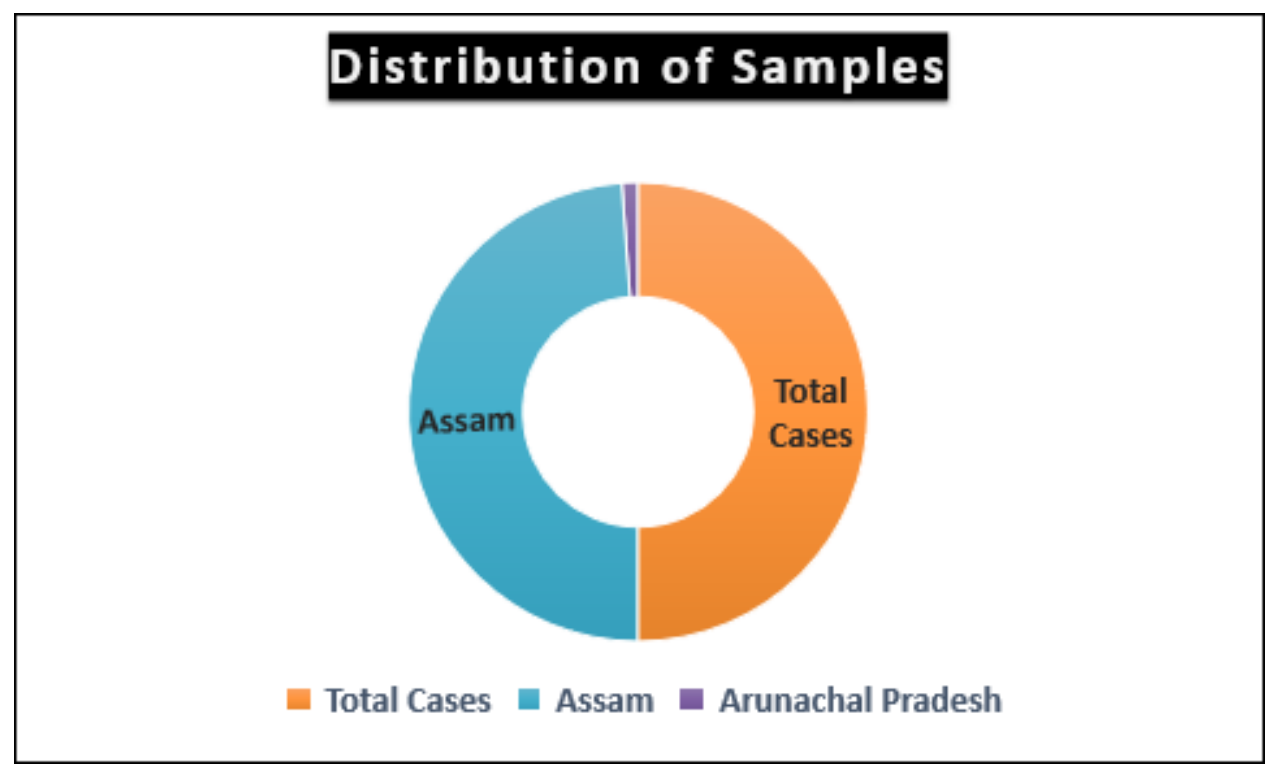

Fig.2 Distribution of Positive cases between Assam and Arunachal Pradesh tested at Virus Research and Diagnostics Laboratory, Tezpur Medical College and Hospital starting from April 2020 to December 2020.

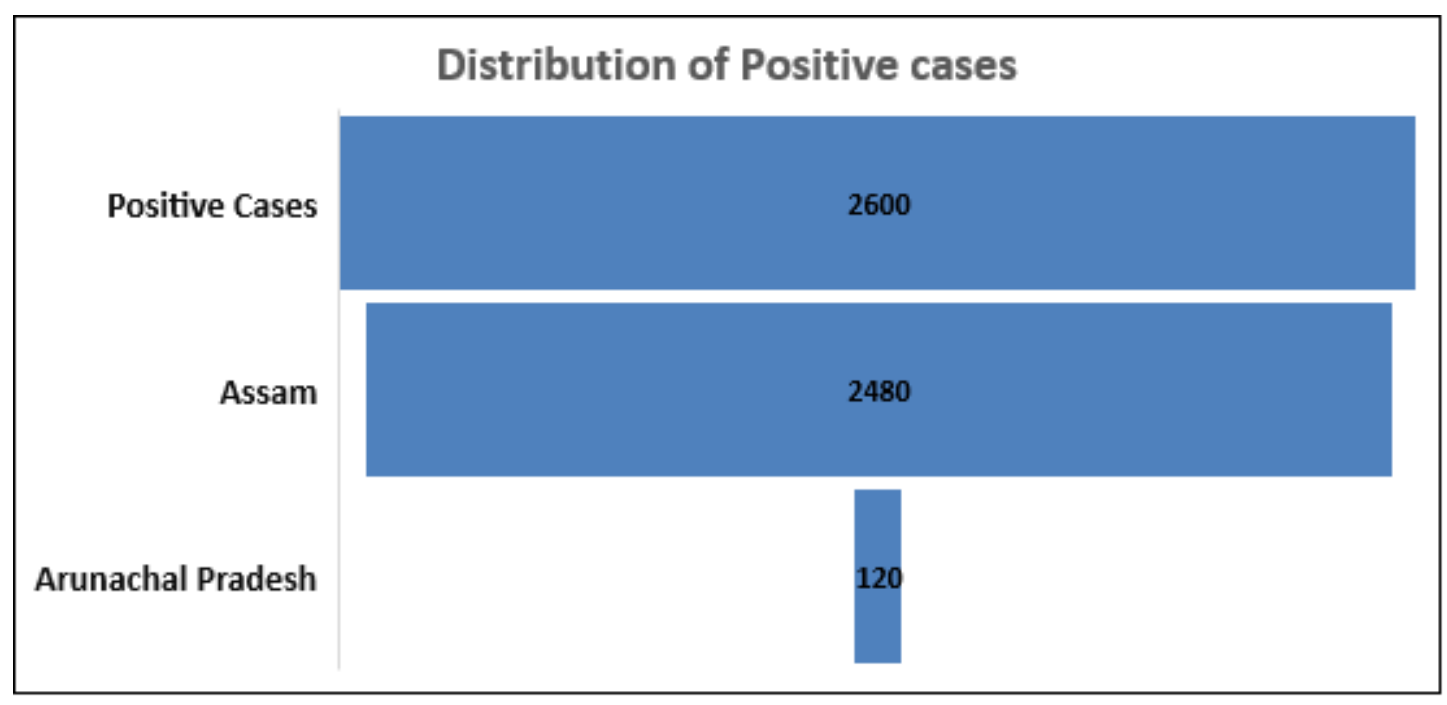


Fig.3 The diagram shows District wise distribution of Positive patients in Assam and Arunachal Pradesh

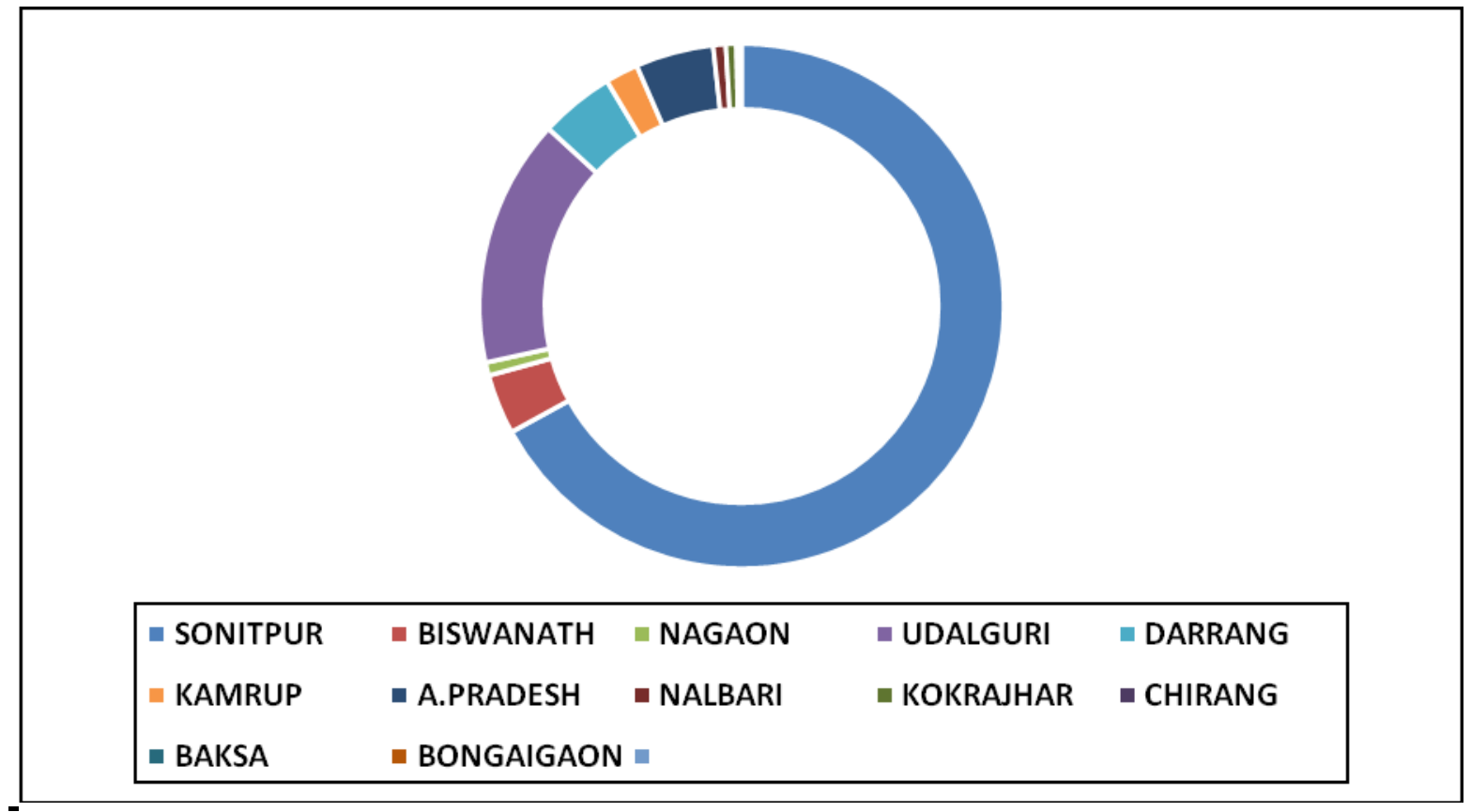

Fig.4 Month wise Covid-19 Cases starting from April 2020 to December 2020 detected at Virus Research and Diagnostics Laboratory, Tezpur Medical College and Hospital. The Maximum Spike in cases was seen in the month of August 2020 followed by a gradual decline in the cases in the state.

\begin{tabular}{|r|c|}
\hline & Monthwise Cases \\
\hline APRIL & \\
\hline MAY & 88 \\
\hline JUNE & 634 \\
\hline JULY & 334 \\
\hline AUGUST & 902 \\
\hline SEPTEMBER & 427 \\
\hline OCTOBER & 152 \\
\hline NOVEMBER & $\mid$ \\
\hline DECEMBER & 2600 \\
\hline TOTAL & \\
\hline
\end{tabular}


Fig.5 A Pareto chart describing the Age wise distribution of Covid-19 cases in descending order of frequency with a secondary axis showing the percentage of the total. Interestingly younger aged people were found to be more vulnerable to the disease with people aged between 20-29 and 30-39 showing the maximum spike.

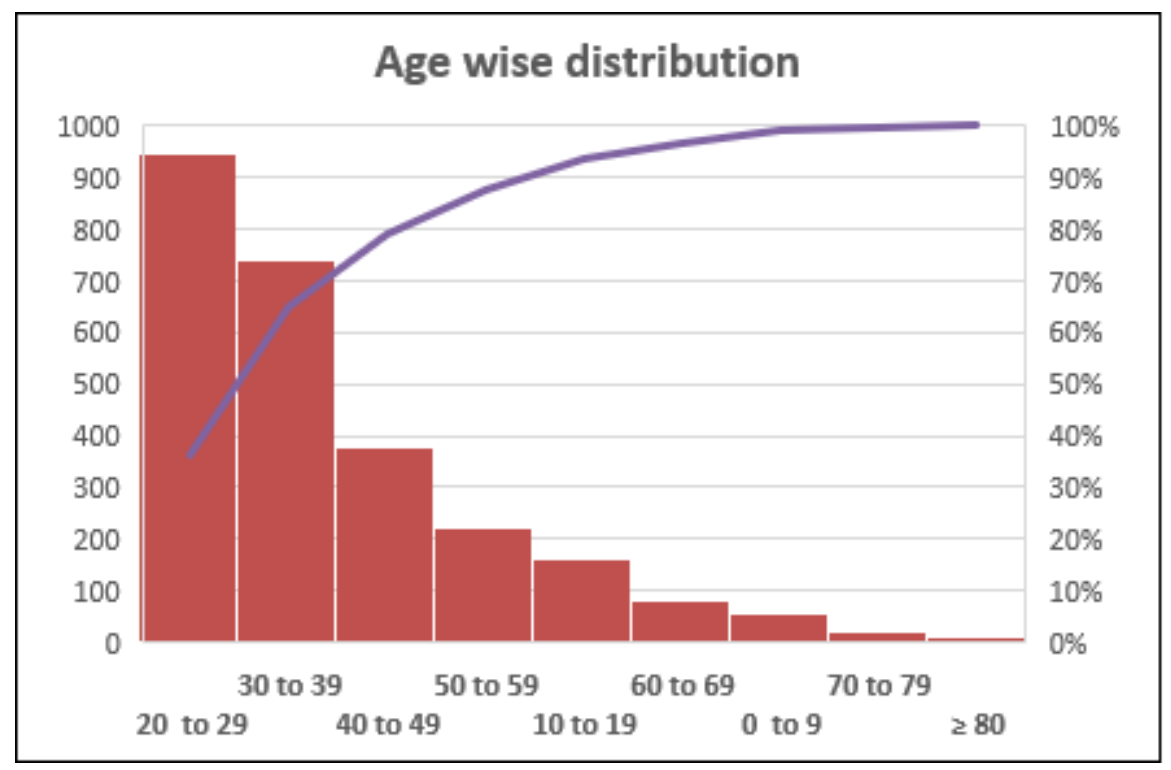

Fig.6 Age and Gender wise Distribution of Covid-19 Cases. The positivity ratio between male and female was seen to be 4:1 showing that males were more vulnerable to the disease as compared to females.

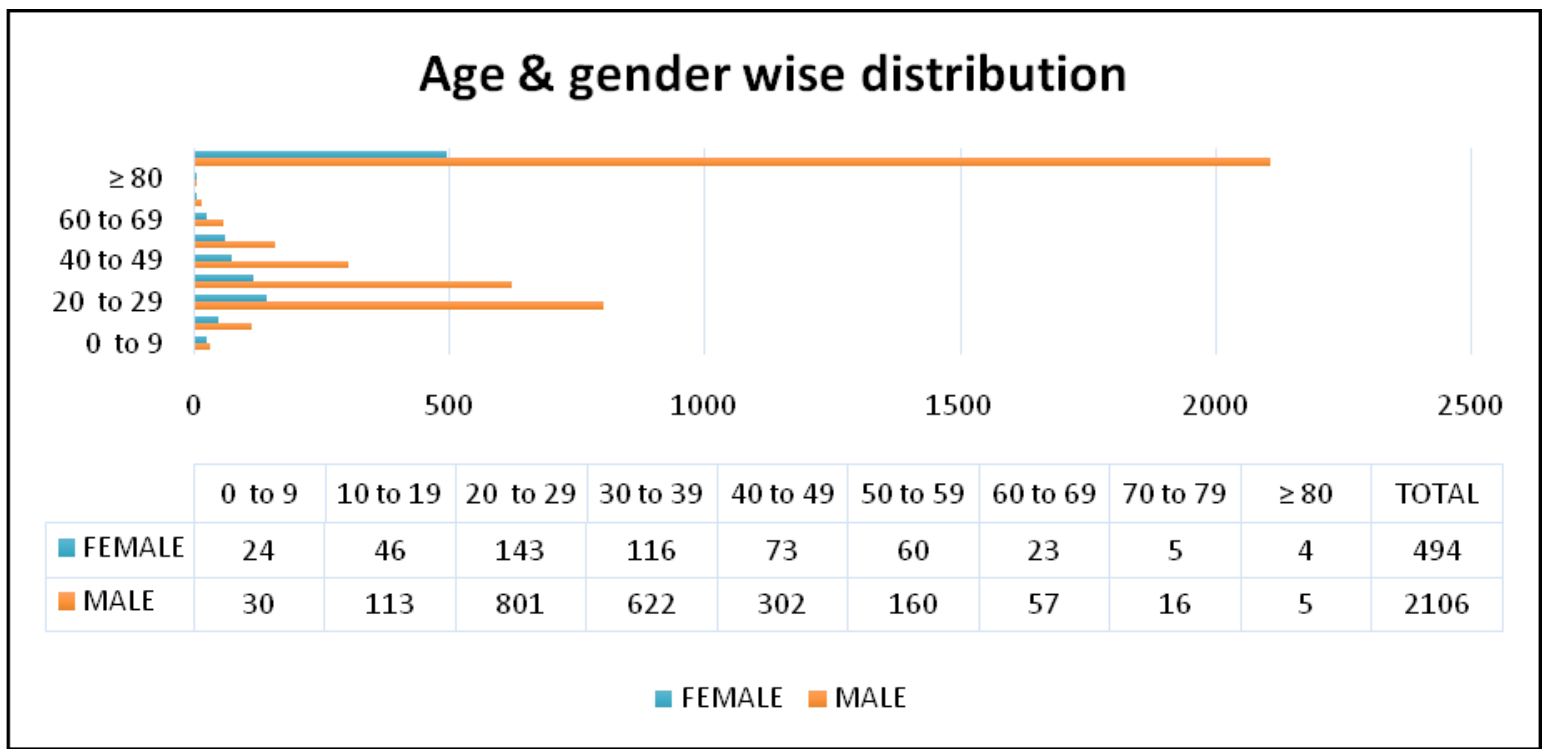

In a study man accounted for $55.4 \%$ of cases and women for $44.6 \%$ COVID-19 cases (Ortiz-Prado et al., 2021). ICMR data also shows that nearly 34 per cent of infected people in India are under the age of 30 years. Experts said higher COVID-19 infection in young India is directly linked to their ratio of population (Huang et al., 2020). 60.3\% of all 
cases were found to be males in a study among 5700 hospitalized COVID-19 patients in the U.S. (Richardson et al., 2021). Our findings were consistent with other reports, in which younger people accounted for most confirmed COVID-19 cases (Guan et al., 2020; Wu \& Googan., 2020; Zhang, et al., 2020).

Although much emphasis was initially placed on the elderly or those who have pre-existing health conditions such as obesity, hypertension, and diabetes as being at high risk of contracting and/or dying of COVID-19, our observation revealed a rather different but interesting finding. Of all the positive COVID-19 cases that were detected at the laboratory, younger aged people were found to be more vulnerable to the disease.

However, this can be attributed to many factors including higher exposure the virus due to more outdoor activities as well as the return of the migrant workers from various parts of the country to the state, sex-based immunological differences driven by sex hormone and $\mathrm{X}$ chromosome, gender behavior (lifestyle), i.e., higher levels of smoking and drinking among men compared to women and irresponsible attitude among men as compared to women such as frequent hand washing, wearing of face mask, and stay at home orders. In addition, children had the lowest burden of disease, possibly due to early school closure and vacation breaks during that period. However, this needs further validation at larger number of samples and epidemiological studies in the region.

Sex difference in the prevalence and outcome of infectious diseases occur at all ages, with an overall higher burden of bacterial, viral, fungal and parasitic infections in human males. (Sawyer, 2012; Flanagan et al., 2017; Klein \& Flanagan, 2016; Schroder et al., 1998). Previous coronavirus outbreaks MERS-CoV and SARS CoV have also been found to infect more men than women (Channappanavar et al., 2017; Badawi et al., 2016. The Saudi Arabian MERS outbreak in 2013 - 2014 exhibited a case fatality rate of $52 \%$ in men and $23 \%$ in women (Alghamdi et al., 2014). These data suggest that, whilst socioeconomic factors may be influencing some aspects of the pandemic, fundamental differences in the immune response between males and females are likely to be a driving factor behind the significant sex-bias observed in the COVID-19 pandemic. Sex differences in both the innate and adaptive immune system have been previously reported and may account for the female advantage in COVID19. Within the adaptive immune system, females have higher numbers of CD4+ T cells (Abdullah, et al., 2012; Lisse, et al., 1997; Delmas, et al., 1997; Mori, et al., 2015; Ruel, et al., 2011) more robust $\mathrm{CD} 8+\mathrm{T}$ cell cytotoxic activity, and increased $\mathrm{B}$ cell production of immunoglobulin compared to males (Abdullah, et al., 2012; Stoica et al., 1980). The less susceptibility to infection among women could be attributed to the $\mathrm{X}$ chromosome and sex hormones, which have been reported to play role in innate and adaptive immunity (Jaillon et al., 2017).

COVID-19 shows less severe pathogenesis but higher transmission competence, as is evident from the continuously increasing number of confirmed cases globally. Early diagnosis by real-time PCR and next-generation sequencing has facilitated the identification of the pathogen at an early stage, which has facilitated the containment of positive cases. We hope we can limit the spread and impact of Covid-19 with a strong determination in policies by the central and state governments.

Present trends suggest the occurrence of future outbreaks of CoVs due to changes in climate, and ecological conditions may be associated with human-animal contact. The present 
outbreak caused by SARS-CoV-2 was indeed expected. Similar to previous outbreaks, the current outbreak will also be contained shortly. However, the real question is, how are we planning to counter the next zoonotic $\mathrm{CoV}$ epidemic that is likely to occur within the next 5-10 years or perhaps within a lesser time.

Current SARS-CoV-2 pandemic has given all of us a big lesson as well as served as reminder of how novel pathogens can rapidly emerge, mutate and spread and leads to public health crises globally.

This study gives an insight about the association of age and gender with COVID-19 cases, as it was found out that most affected group was in the younger age group in both males and females. Males were affected more than female. Less positive cases were observed in this part of Assam as early lockdown and implementation of all preventive measures were taken to control the spread of disease.

The variation in infection rate and chances of recovery across age and gender might be based on the biological variations (immunological and genetic differences). Further research should be conducted to investigate replication, transmission dynamic and pathogenesis in humans. It will help to develop potential therapeutics against zoonotic $\mathrm{CoV}$ epidemics in near future. We hope we can limit the spread and impact of COVID-19 infections and frame a strong public health policies based on age and gender specific by the central and state governments.

\section{Acknowledgements}

The authors are grateful to the ICMR, New Delhi, India for all the support throughout this COVID-19 pandemic. Also, to the entire faculty, Research Scientist, staffs, laboratory Technicians and Data entry operators working in VRDL, Department of Microbiology, Tezpur Medical College \& Hospital for their kind cooperation throughout the period.

\section{Conflict of interest statement}

We declare that we have no conflict of interest.

\section{References}

Abdullah, M., et al., (2012). Gender effect on in vitro lymphocyte subset levels of healthy individuals. Cell. Immunol., 272: 214-219.

Alghamdi, I. G., et al., (2014). The pattern of Middle East respiratory syndrome coronavirus in Saudi Arabia: a descriptive epidemiological analysis of data from the Saudi Ministry of Health. Int J. Gen. Med., 7: 417-423.

Badawi, A., Ryoo, S. G. J. I., Jo, I. D. (2016). Prevalence of comorbidities in the Middle East respiratory syndrome coronavirus (MERS-CoV): a systematic review and metaanalysis. Int. J. Infect. Dis., 49: 129-133.

Channappanavar, R., Fett, C., Mack, M., Ten Eyck, P. P., Meyerholz, D. K., Perlman, S. (2017). Sex-based differences in susceptibility to severe acute respiratory syndrome coronavirus infection. J. Immunol. 198: 4046-4053.

Chen, Y., Liu, Q., Guo, D. (2020). Emerging coronaviruses: genome structure, replication, and pathogenesis. J. Med. Virol. $\quad 10.1002 / j m v .25681$. doi:10.1002/jmv. 25681.

COVID-19 India $9^{\text {th }}$ April 2021 12:20 Pm IST (https://www.covid19india.org).

Delmas, M. C., et al.,(1997). Gender difference in CD4+cell counts persist after HIV-1 infection. SEROCO Study Group. AIDS, 11: 1071-1073.

Flanagan, K. L., Fink, A. L., Plebanski, M., 
Klein, S. L.(2017). Sex and Gender Differences in the Outcomes of Vaccination over the Life Course. Annu Rev. Cell Dev. Biol., 33 : 577599.

Ghinai, T. D., Mcpherson, J. C., Hunter, H. L., Kirking, D., Christiansen, K., Joshi, T. M. (2020). First known person-toperson transmission of severe acute respiratory syndrome coronavirus 2 (SARS-CoV-2) in the USA. The Lancet.,395 (10230):1137-1144. doi: 10.1016/s0140-6736(20)30607-3.

Guan, W. J., Ni, Z.Y., Hu, Y., Liang, W. H., Ou, C.Q., He, Jx., et al., (2020). Clinical characteristics of Coronavirus disease 2019 in China. N. Engl. J. Med. Doi: http:// dx.doi.org/10.1056/NEJ Moa 2002032.

Huang, C., Wang, Y., Li, X., Ren, L., Zhao, J., Hu, Y., et al., (2020). Clinical features of patients infected 367 with 2019 novel coronavirus in Wuhan, China. The Lancet, 395(10223): 497506.

Jaillon, S., Berthenet, K., Garlanda, C. (2017). Sexual dimorphism in innate immunity. Clin. Rev. Allergy Immunol., 1-14.

Klein, S. L., and Flanagan, K. L. (2016). Sex differences in immune responses. Nat. Rev. Immunol. 16: 626-638.

Kritas, S. K., Ronconi, G., Caraffa, A., Gallenga, C. E., Ross, R., Conti, P. (2020). Mast cells contribute to coronavirus-induced inflammation: new anti-inflammatory strategy. $J$. Biol. Regul. Homeost. Agents. 34(1): 10.23812/20-Editorial-Kritas. doi: 10.23812/20- Editorial-Kritas.

Li, G., Fan, Y., Lai, Y., Han, T., Li, Z., Zhou, P., Pan, P., Wang, W., Hu, D., Liu, X., Zhang, Q., Wu, J. (2020). Coronavirus infections and immune responses. $J$. Med. Virol., 10.1002/jmv.25685. doi: 10.1002/jmv.25685.
Lisse, I. M., et al., (1997). T-lymphocyte subsets in West African children: impact of age, sex, and season. $J$. Pediatr., 130: 77-85.

Mori, M., et al., (2015). Sex Differences in Antiretroviral Therapy Initiation in Pediatric HIV Infection. PLoS One., 10: e0131591.

Novel coronavirus disease 2019 (COVID-19) pandemic: increased transmission in the EU/EEA and the UK - sixth update. European Centre for Disease Control and Prevention. 2020 Mar 12. URL:

https://www.ecdc.europa.eu/sites/defau lt/files/ documents/RRA-sixth-updateOutbreak-of-novel-coronavirusdisease-2019-COVID-19.pdf [accessed 2020-04-05].

Ortiz-Prado, E., Simbaña-Rivera, K., Barreno, L. G., Diaz, A. M., Barreto, A. Moyano, C. et al., (2021). Epidemiological, socio-demographic and clinical features of the early phase of the COVID-19 epidemic in Ecuador. PLoS Negl. Trop. Dis., 15(1): e0008958.

Richardson, S., Hirsch, J. S., Narasimhan, M., Crawford, J. M., McGinn, T., Davidson K. W., et al., (2021). Presenting characteristics, comorbidities and outcome among 5700 patients hospitalized with COVID-19 in the New York city area. JAMA. 323: 2052.

Ruel, T. D., et al., (2011). Sex differences in HIV RNA level and CD4 cell percentage during childhood. Clin. Infect. Dis. 53: 592-599.

Sawyer, C. C. (2012). Child mortality estimation: estimating sex differences in childhood mortality since the 1970 s. PLoS Med., 9: e1001287.

Schroder, J., Kahlke, V., Staubach, K. H., Zabel, P., Stuber, F. (1998). Gender differences in human sepsis. Arch. 
Surg., 133: 1200-1205.

Stoica, G., Macarie, E., Michiu, V., Stoica, R. C. (1980). Biologic variation of human immunoglobulin concentration. I. Sexage specific effects on serum levels of $\mathrm{IgG}, \operatorname{Ig} \mathrm{A}, \mathrm{IgM}$ and $\mathrm{IgD}$. Med. Interne. 18: 323-332.

Weiss, S. R., Leibowitz, J. L. (2011). Coronavirus pathogenesis. Adv. Virus Res. 81: 85-164. doi: 10.1016/B978-012-385885-6.00009-2.

WHO Coronovirus (COVID-19) dashboard (from $3^{\text {rd }}$ January2020 to $4: 08 \mathrm{pm}$ CEST8 April 2021.

Wu, Z., Mc Googan, J. M. (2020). Characteristics of and important lessons from the coronavirus disease 2019 (COVID-19) outbreak in China: Summary of a report of 72314 cases from the Chinese center for Disease control and prevention. JAMA, 323(13):1239-1242.doi.

http://dx.doi.org/10.1001/jama:

2020.2648.

Zhang, J., Litvinova, M., Liang, Y., Wang, Y., Wang, W., Zhao, S., et al., (2020). Changes in contact pattern shape the dynamics of the COVID-19 outbreak in China. Science. doi: http://dx.doi.org/10.1126/science.abb 8001 .

Zhu, N., Zhang, D., Wang, W., Li, X., Yang, B., Song, J., Zhao, X., Huang, B., Shi, W., Lu, R., Niu, P., Zhan, F., Ma, X., Wang, D., Xu, W., Wu, G., Gao, G.F., Tan, W.(2020). China Novel Coronavirus Investigating and Research Team, A Novel Coronavirus from Patients with Pneumonia in China, 2019. N. Engl. J. Med., 10.1056/NEJMoa2001017. doi: 10.1056/NEJMoa2001017.

\section{How to cite this article:}

Syed Tanwir Alam, Samrat Biswas, Kalpana Bezborah, Sonuwara Begum, Mihirjyoti Pathak, Saurav Phukan, Pitambar Baishya, Kaushik Das, Jasbeer Singh Roy, Sanjay Sarkar, Simi Borah and Miranda Khuttiya. 2021. A Retrospective Study of COVID-19 Cases Based on Age and Gender in Patient's Visiting Tertiary Care Centre, Tezpur Medical College and Hospital, Tezpur, Assam. Int.J.Curr.Microbiol.App.Sci. 10(09): 128-139. doi: https://doi.org/10.20546/ijcmas.2021.1009.015 